\title{
Dissemination of Pertussis in Pregnant Women of Iran
}

\author{
Shima Javadinia ${ }^{1}$, Ali Badamchi ${ }^{2}$, Zahra Movahedi $^{3}$, Mehdi shokrabi ${ }^{4}$, Maryam sadeghi $^{2}$, Leila Tahernia $^{4}$, \\ Mahbod Jafarvand ${ }^{4}$ and Azardokht Tabatabaei ${ }^{4 *}$ \\ ${ }^{1}$ Imam Khomeini Hospital, Tehran University of Medical Sciences, Iran \\ ${ }^{2}$ Children's Medical Center Hospital, Tehran University of Medical Sciences, Iran
}

${ }^{3}$ Research Center of Pediatric Infectious Disease, Qom University of Medical Sciences and Health services, Qom, Iran.

${ }^{4}$ Research Center of Pediatric infectious diseases, Iran University of Medical Sciences, Iran

Submission: March 10, 2018; Published: May 04, 2018

${ }^{*}$ Corresponding author: Azardokht Tabatabaei, Research Center of Pediatric infectious diseases, Rasool Akram Hospital, Iran University of Medical Sciences, Iran, Tel: +982166516049; Email: Azardokht_tabatabaei@yahoo.com

Abstract

Aim: Pertussis is severe illness and high mortality, especially among infants. The aim of this study was to determine the prevalence of Bordetella pertussis in pregnant women in southern part of Tehran.

Methods: Total 303 pregnant women who referred to health centers for periodic pregnancy tests were randomly selected during six months in the year 2017. After receiving conscious consent from mothers, 5 milliliter of blood was sampled. A test to determine quantitative values of IgG-pT, IgA-pT by ELISA method was performed on samples.

Results: In total, 177 women (58.2\%) were serologically infected with Bordetella pertussis. Only 27 women (8.9\%) had cough symptom during pregnancy. The mean levels of IgG-pT, IgA-PT during pregnancy were 37.24 and 5.79, respectively. The mean IgG-pT antibody level in the first trimester of pregnancy was higher than average IgG-pT levels around the time of delivery (38.39 U/ml versus $34.74 \mathrm{U} / \mathrm{ml}$ ).

Conclusion: Due to high exposure of Iranian mothers to pertussis and high prevalence of pertussis among children under the age of six months, it is crucial to prescribe acellular pertussis vaccine in women during pregnancy, upon discharge from the hospital.

Keywords: Pregnancy; Cough; IgG -PT; IgA-PT; Pertussis

\section{Introduction}

Infectious diseases remain a major cause of mortality in children between ages 0 to 2 years-old. More than 1.5 million deaths from vaccine-preventable infectious diseases occur in children throughout the world [1]. Vaccination can prevent severe infections and reduce its devastating effects. [2] But there is no vaccination between childhood and pregnancy in women against vaccine-preventable infectious agents. For this reason, immunization of pregnant women as an important strategy replaces fight against infectious agents in neonatal period [2]. Pertussis is severe illness and high mortality, especially among infants [3]. The incidence of pertussis is increasing in most developed countries despite vaccination coverage of over $90 \%$. [4]. Vaccination coverage in Iran against pertussis is more than $98 \%$. The overall incidence of disease in Iran is 1.12 per 100,000 people [5]. Pregnant women suffering from pertussis during delivery, depending on the onset of infection in the mother, have the ability to infect their children before receiving maternal antibodies through placenta. The aim of this study was to determine the prevalence of pertussis infection in pregnant women.

\section{Materials and Methods}

Studied population included all pregnant women who referred to health centres for periodic routine pregnancy tests during six months of the year 2017. According to this study, total 303 pregnant women randomly were selected. After obtaining conscious consent from mothers, $5 \mathrm{ml}$ of blood was sampled and simultaneously a questionnaire was completed. After serum isolation; it was stored in freezer at minus $20^{\circ} \mathrm{C}$ before analysis. Determination of Specific immunoglobulin's against pertussis toxins IgG-pT, IgA-pT were performed with kit purchased from German IBL Company. The ELISA test was carried out at Infectious Disease Research Centre of Rasool Akram Hospital. The Ethics Committee approved this research and $\mathrm{P}$ value less than 0.05 was considered statistically significant. 


\section{Results}

During six months, 303 pregnant women were studied. The mean age at pregnancy was 27.59 years [range $15-45$ years].The mean gestational age was 89.03 days. $95 \%$ of women claimed childhood vaccination against pertussis but $5 \%$ of women could not remember their childhood vaccination against pertussis. The majority of women had antibody levels of 3.5-221IU/ml at 26 weeks of gestation. $58.2 \%$ of women (177 cases) had an antibody level greater than 24IU / ml. IgG-pT concentration below $24 \mathrm{IU} /$ $\mathrm{ml}$ was reported in 127(41.8\%) women. IgG-pT level greater than $100 \mathrm{IU} / \mathrm{ml}$ was observed in (5.92\%) 18 pregnant women.

In total, 177 women (58.2\%) from total 303 women were reported with antibodies level greater than $24 \mathrm{IU} / \mathrm{ml}$ and considered positive for pertussis based on German IBL company criteria. Only $27 \%$ (8.9\%) of women had a history of cough during pregnancy. The mean levels of IgG-PT, IgA-PT during pregnancy were 4.82 and $37.5 \%$, respectively. The mean IgG-pT antibody levels in subjects in the first trimester of pregnancy were higher than levels near delivery in the third trimester of pregnancy (38.39 versus $34.74 \mathrm{IU} / \mathrm{ml}$ ) which indicated pertussis infection during pregnancy.

\section{Discussion}

Moreover, a woman who does not have protective antipertussis antibodies cannot pass the protection to her child during pregnancy, thus the newborn is susceptible to the disease. In this age group, pertussis may be severe and lifethreatening [5]. Despite high levels of vaccination in childhood, we have found evidence that Bordetella infections have spread to 18 pregnant women during pregnancy. 40 women $(13.15 \%)$ had an antibody level of 100-150 IU / ml. Although this level is not attributed to recent or active infection, it indicates Bordetella pertussis infection in previous year. 53 women (17.3\%) of total pregnant women in our study were serologically positive for Bordetella pertussis during or before gestation, which is much higher than reported cases in this age group in Hamadan $(35.8 \%)$, which indicates an increase in incidence of pertussis in pregnant women and infants under the age of six months [6].

Zatsu et al. in Russia conducted a study on 102 pregnant women who measured antibody levels against pertussis. More than $66 \%$ of pregnant women had no antibodies against pertussis and only $5.22 \%$ had suitable antibody titer for protection [7]. The results from similar studies in other regions reflected different levels of antibody protection, such as 33\% in Spain [8], $55 \%$ in Japan [9], 88\% in Slovenia [10], and 97\% in Singapore [11].Therefore, the high seroprevalence of pertussis antibodies among adults might be related to the pertussis epidemic. These findings support our interpretation that a pertussis epidemic can cause an increase in the seroprevalence of anti-PT IgG among adults.

There is some evidence that maternal antibodies protect newborns against pertussis, because IgG-PT is transmitted from mother to embryo [12]. Mothers in our study had an antibody level below $40 \mathrm{IU} / \mathrm{ml}$ during pregnancy. Mother's, who had high level of IgA antibody in the last days of pregnancy, were newly involved.

In spite of $99 \%$ vaccination coverage against pertussis in Iran, similar to other countries, the incidence of pertussis increased from the year 2004 (98 cases), to 2011 (650 cases). The most common cases of pertussis was related to infants under the age of 2 months-old Positive result was more common in age group under two months-old than those of other age groups $[13,14]$. These children most likely received pertussis infection from their parents when most cases occur in the first months of life, immunizing pregnant women could represent a successful strategy to protect infant by transferring maternal antibodies. Due to high exposure of Iranian mothers with pertussis and high prevalence among children under age of two years, it is urgent to use an acellular vaccine in pregnant women during pregnancy, upon discharge from the hospital.

\section{Acknowledgments}

The authors acknowledge Research Center of Pediatric infectious diseases, Rasool Akram Hospital, Iran University of Medical Sciences.

\section{References}

1. Jean-Marie Okwo-Bele (2015) Together we can close the immunization gap. World Health Organization, Geneva, Switzerland.

2. Lambert P-H, Liu M, Siegrist CA (2005) Can successful vaccines teach us how to induce efficient protective immune responses? Nature medicine 11: 54-62.

3. Chiappini E, Stival A, Galli L (2013) Pertussis re-emergence in the postvaccination era. BMC infectious diseases 13(1): 151.

4. Winter K, Harriman K, Zipprich J (2012) California pertussis epidemic. The Journal of pediatrics 161(6): 1091-1096.

5. Raya BA, Bamberger E, Almog M (2015) Immunization of pregnant women against pertussis: the effect of timing on antibody avidity. Vaccine 33(16): 1948-1952.

6. Hashemi SH, Zamani M, Mamani M (2014) Seroprevalence of Bordetella pertussis antibody in pregnant women in Iran. Journal of research in health sciences 14(2): 128-131.

7. Za'tsev E, Krasnoproshina L, Astakhova T (2010) Monitoring of antibodies against diphtheria, tetanus and pertussis in pregnant women. Zhurnal mikrobiologii, epidemiologii, i immunobiologii (1): $32-35$.

8. Diez-Domingo J, Ballester A, Baldó J-Ma (2004) Incidence of pertussis in persons $\leq 15$ years of age in Valencia, Spain: seroprevalence of antibodies to pertussis toxin (PT) in children, adolescents and adults. Journal of Infection 49(3): 242-247.

9. Okada K, Ueda K, Morokuma K (2004) Seroepidemiologic study on pertussis, diphtheria, and tetanus in the Fukuoka area of southern Japan: seroprevalence among persons $0-80$ years old and vaccination program. Japanese journal of infectious diseases 57(2): 67-71.

10. Sočan M, Prosenc K, Vegnuti M (2006) Seroprevalence of IgG antibodies to pertussis toxin in the Slovene population. Wiener klinische Wochenschrift 118(11-12): 336-340. 
11. Wilder-Smith A, Ng S, Earnest A, Earnest A (2006) Seroepidemiology of pertussis in the adult population of Singapore. Annals-Academy of Medicine Singapore 35(11): 780.

12. Amirthalingam G, Andrews N, Campbell H (2014) Effectiveness of maternal pertussis vaccination in England: an observational study. The Lancet 384(9953): 1521-1528.
13. Nikbin VS, Shahcheraghi F, Lotfi (2013) Comparison of culture and realtime PCR for detection of Bordetella pertussis isolated from patients in Iran. Iran J Microbiol 5(3): 209-214.

14. Badamchi A, Papizadeh M (2017) Comparative Phylogeny of the Genus Bordetella Using Sequence Analysis of 16S rRNA and ompA Genes. Journal of Medical Bacteriology 6(3-4): 1-13.

\section{Your next submission with Juniper Publishers will reach you the below assets}

- Quality Editorial service

- Swift Peer Review

- Reprints availability

- E-prints Service

- Manuscript Podcast for convenient understanding

- Global attainment for your research

- Manuscript accessibility in different formats

( Pdf, E-pub, Full Text, Audio)

- Unceasing customer service

Track the below URL for one-step submission https://juniperpublishers.com/online-submission.php 